\title{
Effects of L-NAME, DEXA, and L-NAME+DEXA on systemic blood pressure of hypertensive pregnant and non-pregnant Wistar Albino rats
}

\section{Gülsüm Bacak ${ }^{1}$ Muharrem Balkaya ${ }^{2 *}$}

\section{Research Article}

Volume: 2, Issue: 3 December 2018

Pages: 78-85

\section{Article History}

Received: 17.09.2018

Accepted: 22.10.2018

Available online:

22.10.2018
1. Ege University Education and Research Hospital Gynecology and Obstetrics Service, Bornova, İzmir, Turkey. 2. Department of Physiology Faculty of Veterinary Medicine, Adnan Menderes University, 09016, Işıklı-Aydın, Turkey.

\begin{abstract}
Objective: NO-inhibition has no effect on blood pressure (BP) of some spontaneous hypertensive animals, but when combined with dexamethasone (DEXA), it increases BP. The study compared effects of L-NAME and/or DEXA on systemic BP of spontaneously hypertensive pregnant and nonpregnant Wistar albino rats. Method: In two simultaneous experiments 62 female rats were used. All animals were mated for 7 days. Sperm positive $(n 1=33)$ and negative $(n 2=29)$ animals were each divided randomly into 4 groups. BPs were recorded in both experiments on the $15^{\text {th }}$ day from tails indirectly, and then animals were given Physiologic Saline (Controls), L-NAME (150mg/ $\mathrm{kg} /$ day), DEXA $(100 \mu \mathrm{g} / \mathrm{kgBW} /$ day) or L-NAME+DEXA (150mg and 100- $\mu \mathrm{g}$ per $\mathrm{kg}$ BW/day) for consequent 5 days. At $19^{\text {th }}$ day, BPs were measured again, before applications. Then, animals put into individual metabolic cages for 24-h urine collection. Thereafter, blood was collected under ether anesthesia, animals were euthanized and necropsied. Weights of animals (BWs), left kidneys, adrenal glands, and fetuses; food consumptions; 24-h urine volume; urinary proteins, blood glucose, and fetus numbers were determined. Data were analyzed by ANOVA and ANOVA for repeated measures. Results: In pregnant animals, L-NAME had higher BWs than DEXA and LNAME+DEXA ( $P=0.021$ and $P=0.012$, respectively). In non-pregnant animals, DEXA reduced $B W s$ significantly compared with controls $(P=0.042)$. Interventions influenced only the diastolic blood pressure of pregnant animals $(P=0.043)$. The difference between DEXA and L-NAME+DEXA was significant $(P=0.044)$. The effects of interventions on other variables varied according to whether animals are pregnant or not. Conclusion: L-NAME and/or DEXA did not influence BP in hypertensive rats.
\end{abstract}

Keywords: Wistar albino rats, L-NAME, dexamethasone

DOI: $10.30704 / \mathrm{http}-w w w-j i v s-n e t .460833$

To cite this article: Bacak, G. \& Balkaya, M. (2018). Effects of L-NAME, DEXA, and L-NAME+DEXA on systemic blood pressure of hypertensive pregnant and non-pregnant Wistar Albino rats. Journal.of Istanbul Veterinary Sciences. 2(3), 78 -85. Abbreviated Title: J Ist Vet Sci

\section{Introduction}

Hypertension, characterized by a systolic blood pressure of $\geq 140 \mathrm{mmHg}$ and diastolic blood pressure of $\geq 90 \mathrm{mmHg}$, is one of the most important reasons of premature deaths, and the most important risk factor for cardiovascular diseases in men worldwide (Baker et al., 2007). It may be primary, developing because of environmental or genetic factors, or secondary, with multiple etiologies including vascular, renal, nervous,

*Corresponding Author: Muharrem Balkaya

E-mail: mbalkaya@adu.edu.tr endocrine and nutritional causes. Consequently, there are many risk factors implicating in the genesis of hypertension (Zhang et al. 2013). In general, they include genetic and environmental factors. More than 90-95\% of cases are essential hypertension with yet unknown cause(s), but there are strong shreds of evidence for a possible familial background of the condition. Therefore, several studies targeting genes aimed to explain the genetic roots of various types of hypertension (Bernatova, 2014). However, none of http://dergipark.gov.tr/http-www-jivs-net 
the determined genetic abnormalities yet found to be responsible alone for a significant proportion of hypertension occurring in the general population.

Many other well-known pathophysiological risk factors of the hypertension include: overactivity of the sympathetic nervous system; immune reactivity and inflammation; overproduction of sodium-retaining hormones and vasoconstrictors; long-term dietary high sodium intake as well as low potassium and calcium intakes; disordered (high or inappropriate) renin secretion with consequent high production of angiotensin II and aldosterone; deficiencies in vasodilators including impairments of the nitric oxide (NO) system, prostacyclins and natriuretic peptide; increased secretion and/or activity of vascular growth factors; derangements in expressions of the kininkallikrein system involving in renal salt handling and vascular tone; alterations in cardiac adrenergic receptors and inotropic properties of the heart and systematic vascular tone; altered ion transport at the cellular level; abnormalities or lesions of vasculature due to various reasons including insulin resistance, diabetes and obesity; chronic kidney and lung diseases and activation of circulating proteins interfering with angiogenesis (Török, 2008; Bernatova, 2014).

There are also many pregnancy-related multifactorial disorders with different etiologies and characterized under others by hypertension with or without concomitant proteinuria (WHO, 2005). Preeclampsia and its severe form, eclampsia, are the most important conditions among these.

As for all other conditions and diseases of the men, research animals prove as a valuable tool also to understand the physiopathological mechanisms of hypertension. Because of the dramatic consequences of their implications on mother and their infants and so on the general population, numerous animal models described gaining insight into possible physiopathological mechanisms and treatment options of preeclampsia and eclampsia. The common models use mainly placental oxygen dysregulation, abnormal trophoblast invasion, maternal vascular damage and abnormal maternal-fetal immune interactions (Pennington et al., 2012).

Vascular endothelium produces various vasoactive factors including most potent vasoconstrictors angiotensin II (Ang II) and its mediator endothelin 1 (ET-1) (Cediel et al., 2002). On the other site, endothelium-derived $\mathrm{NO}$ is also the known most potent endogenous vasodilator and a local regulator of the vascular system. Increased production of NO during late gestation decreases systemic vascular resistance under normal conditions (Nathan et al. 1995). Thus, any decrease or failure of the NO contributes to the development of hypertension (Rafikov et al., 2011). Therefore, animal models of preeclampsia via nitric oxide synthase (NOS) inhibition are often preferred as an alternative approach which aims to target mechanisms at the level of the endothelium instead trying to reproduce entire disease (Podjarny et al., 2004). The effects of the LNAME on the uterine vasculature, however, may differ depending on whether animals are pregnant or not (Osol et al., 2009). Púzserová et al. (2007) have also been reported a significant relationship between BP and L-NAME-sensitive component of relaxation of the femoral artery.

Increased production of endogenous glucocorticoids and their parenteral applications or applications of their synthetic analogs (e.g., dexamethasone) results also in hypertension. A recent study demonstrated that the hypertensive effect of glucocorticoids is a consequence of their direct effects on blood vessels (Goodwin et al., 2011). There is also evidence of multiple interactions between NO-system and corticosteroids (Yallampalli et al., 1994; Changbin and Baylis, 2000). Dexamethasone is able to modify $\alpha$ adrenoreceptor-mediated effects of L-NAME on vascular smooth muscles (Adeagbo and Triggle, 1993). However, there is no comparative information about the interactions between L-NAME and corticosteroids regarding systemic blood pressure in pregnant and non-pregnant rats.

This study aimed to determine the effects of NOSinhibition (L-NAME), dexamethasone (DEXA) and the combination of L-NAME and DEXA on blood pressure of both pregnant and non-pregnant Wistar albino rats with a high blood pressure of dietary origin.

\section{Materials and methods}

Study conditions: Institutional Animal Ethics Committee has approved the study (\#2012/105). The study has been carried out in a semi-climatized experimental room with a microenvironment of $23 \pm 1^{\circ}$ $\mathrm{C}$ temperature, $50-70 \%$ relative humidity and $12: 12 \mathrm{~h}$ light:dark cycle, which was similar to their rearing conditions. A total of 62 female Wistar rats (33 pregnant and 29 non-pregnant) were used in two different experiments, which were carried out simultaneously to avoid possible effects of time. Animals were allowed an adaptation period for ten days. Then, all animals were mated on the following 9 days in the harem system. Pregnancy was detected by daily vaginal sperm controls where the sperm [+] day recorded as the beginning of pregnancy (day 0 ) for given animal. During the mating period 33 animals were sperm [+], and 29 sperm [-]. 
The animals received pelleted diet for rats and mice and daily fresh top water throughout the study (including adaptation and mating periods) ad libitum.

L-NAME was given to animals by oral gavage and DEXA by intraperitoneal injections.

Experiment I: In this experiment, 33 pregnant rats were used. Animals were divided randomly into four groups. The animals in Group I served as controls. Animals in other groups were given L-NAME $(150 \mathrm{mg} /$ $\mathrm{kg} / \mathrm{d}$ ) (Group II), DEXA (100 $\mathrm{gg} / \mathrm{kg} / \mathrm{d}$ ) (Group III) or LNAME + DEXA $(150 \mathrm{mg} / \mathrm{kg} / \mathrm{d}+100 \mu \mathrm{g} / \mathrm{kg} / \mathrm{d})$ (Group IV) for 5 days starting at the $15^{\text {th }}$ day of their pregnancy. Animals in the control group were given equal volumes of physiological saline on the same days.

Experiment II: In this experiment 29 non-pregnant animals were divided randomly into four groups as in Experiment I. The animals in Group I served as controls. Animals in other groups were given same amounts of physiological saline, L-NAME (Group II), DEXA (Group III) or L-NAME + DEXA (Group IV) for 5 days; exactly, on the same last 5 days of the experiment, as in Experiment I.

Data collection: The body weights of animals were recorded at the beginning (day 0 ) and $15^{\text {th }}$ and $19^{\text {th }}$ days of the experiments. Blood pressures were recorded via non-invasive method from tails of animals on days 15 and 19 of the experiment before substance applications. On day 19, animals were put into individual metabolic cages for $24 \mathrm{~h}$ after blood pressure measurements, and $24 \mathrm{~h}$-urine samples were collected on day 20 of the experiment. Thereafter, 4-5 $\mathrm{ml}$ blood samples were collected by hearth punctures under ether anesthesia, and then the animals were euthanized. Body weights, and weights of the suprarenal glands and left kidneys and fetuses' numbers (in Experiment I) were recorded from necropsied animals.

Laboratory analysis: Protein concentrations were determined ad modum Esbach in urine samples, and glucose concentrations were determined via glucometer in blood samples, both by using strips.

Blood pressures measurements: Systolic and diastolic blood pressures were recorded from animals by noninvasive, indirect method (NIBP 200-A, Commat ${ }^{\circledR}$, Ankara, Turkey). For this reason, animals were transported in pre-warmed recording room 2 hours before the measurements. Then, shortly before measurements they held for 15-20 minutes in a heated measurement box with inner temperature of 33-34 ${ }^{\circ} \mathrm{C}$. Measurements were carried out when animals were relaxed and regular waves occurred. Three subsequent measurements were made from each animal.

Data were recorded, stored and evaluated by Biopac Version 3.7.2 Program (BIOPAC Systems, Inc. Aero Camino, USA).

Statistical analyses: SPSS for Windows ${ }^{\circledR}$ Version 21 was used to store and analyze the data gathered. Data were analyzed via ANOVA and ANOVA for repeated measures in factor time. Tukey test was used as post hoc. $\mathrm{P} \leq 0.05$ was accepted as significant.

\section{Results}

Body weights: The body weights changes of the female Wistar rats are summarized in Table 1 . There was no significant difference in mean body weights of both pregnant and non-pregnant animals at the beginning of the experiments ( $P>0.05)$.

During the 3-weeks experimental period, body weights of pregnant rats showed remarkable changes. The effects of interventions on the body weights of pregnant rats were significant $(P=0.006)$. Paired comparisons for groups revealed significant differences for the groups given L-NAME, DEXA, and LNAME + DEXA. Namely, the average body weight of the group given L-NAME was higher than those given DEXA and L-NAME + DEXA $(P=0.025$ and $P=0.014$ respectively). Analysis of variance for repeated

Table 1. Body weights of animals [g]

\begin{tabular}{|c|c|c|c|c|c|c|}
\hline \multirow[t]{2}{*}{ Groups } & \multicolumn{3}{|c|}{$\begin{array}{l}\text { Pregnant rats } \\
\qquad \overline{\mathbf{x}} \bar{F}_{\mathrm{x}}\end{array}$} & \multicolumn{3}{|c|}{$\begin{array}{l}\text { Non-pregnant rats } \\
\qquad \overline{\mathrm{X}} \mp \mathrm{Sx}_{\mathrm{x}}\end{array}$} \\
\hline & Day 0 & Day 15 & Day 20 & Day 0 & Day 15 & Day 20 \\
\hline Control & $214 \pm 19$ & $294 \pm 22$ & $317 \pm 30$ & $217 \pm 08$ & $268 \pm 42$ & $273 \pm 44^{*}$ \\
\hline L-NAME & $227 \pm 21$ & $313 \pm 20^{*}$ & $315 \pm 27$ & $215 \pm 50$ & $255 \pm 36$ & $236 \pm 29$ \\
\hline DEXA & $201 \pm 07$ & $274 \pm 12^{\Omega}$ & $286 \pm 16$ & $202 \pm 22$ & $223 \pm 23$ & $209 \pm 18^{\Omega}$ \\
\hline L-NAME + DEXA & $213 \pm 22$ & $282 \pm 34^{\Omega}$ & $269 \pm 32$ & $215 \pm 13$ & $258 \pm 36$ & $216 \pm 28$ \\
\hline
\end{tabular}

In the same colon* $\Omega$ : $P<0.05$ 
Bacak, G. \& Balkaya, M. 2018 / Journal of Istanbul Veterinary Sciences. Volume 2, Issue 3, pp: 78-85

Table 2: Blood Pressures of Rats [mmHg]

\begin{tabular}{lcccc}
\hline \multirow{2}{*}{ Groups } & \multicolumn{2}{c}{ Pregnant rats } & \multicolumn{2}{c}{ Non-pregnant rats } \\
& $15^{\text {th }}$ day & \multicolumn{4}{c}{$\begin{array}{c}\text { th } \text { day } \\
\text { Systolic blood pressures }\end{array}$} \\
Control & $165.38 \pm 18.84$ & $151.57 \pm 10.26$ & $148.29 \pm 16.70$ & $135.57 \pm 20.07$ \\
L-NAME & $144.67 \pm 11.09$ & $142.50 \pm 18.15$ & $146.29 \pm 10.08$ & $153.43 \pm 12.31$ \\
DEXA & $150.0 \pm 19.28$ & $143.78 \pm 15.92$ & $133.14 \pm 07.03$ & $150.86 \pm 10.89$ \\
L-NAME + DEXA & $154.56 \pm 20.43$ & $161.22 \pm 18.38$ & $122.25 \pm 19.64$ & $151.14 \pm 22.70$ \\
& & Diastolic blood pressures & \\
Control & $134.50 \pm 18.45$ & $123.29 \pm 05.47$ & $122.57 \pm 14.55$ & $115.57 \pm 15.97$ \\
L-NAME & $118.33 \pm 13.80$ & $117.38 \pm 14.61$ & $117.71 \pm 08.12$ & $132.29 \pm 13.09$ \\
DEXA & $118.0 \pm 18.29$ & $115.44 \pm 11.18$ & $109.0 \pm 09.13$ & $119.29 \pm 10.08$ \\
L-NAME + DEXA & $125.67 \pm 14.77$ & $132.22 \pm 16.09$ & $104.38 \pm 14.46$ & $135.43 \pm 22.84$ \\
\hline
\end{tabular}

measures in factor time revealed that the effect of time was significant, and there was a significant interaction between the time and interventions $(P=0.000)$. Paired comparisons for time revealed significant differences between the $1^{\text {st }}$ and $2^{\text {nd }}$ and $1^{\text {st }}$ and $3^{\text {rd }}$ measurement points $(P=0.000)$. However, the differences between the $2^{\text {nd }}$ and $3 \mathrm{rd}$ measurements were not confirmed statistically ( $\mathrm{P}=0.058, \% 95 \mathrm{Cl}$ : $12.157-.150)$.

However, the effects of the interventions on the body weights of non-pregnant animals could not be confirmed statistically ( $P=0.066, F=2,729)$. Also, paired comparisons for groups did not confirm the difference in mean body weights of controls and DEXA ( $P=0.054$, $\% 95 \mathrm{Cl}:-.494-83,065)$. In contrast, the effect of time on the body weights of non-pregnant animals and the interaction between time and interventions proved to be significant $(P=0.000)$. Paired comparisons for time revealed significant differences between the $1^{\text {st }}$ and $2^{\text {nd }}, 1^{\text {st }}$ and $3^{\text {rd }}$ and $2^{\text {nd }}$ and $3^{\text {rd }}$ measurements $(\mathrm{P}=0.000, \mathrm{P}=0.007$ and $\mathrm{P}=0.0000$ respectively).

Systolic and diastolic blood pressures: Mean blood pressure values are presented in Table 2.

In pregnant rats, there was no significant difference in mean systolic blood pressure values, when recorded at day 15 before interventions. Statistical analysis did also not confirm the effects of interventions on systolic blood pressures recorded at day $19(P=0.083, F=2.456)$. The effect of time and interactions between time and interventions were also not significant $(P>0.05)$.

There were significant differences in mean systolic blood pressure values of the non-pregnant Wistar albino rats at day 15 of the experiment, also before interventions. Post hocs revealed lower mean systolic blood pressure of the L-NAME + DEXA group when compared with control and DEXA groups $(P=0.010$ and $P=0.018$ respectively). However, no significant

Table 3. Other Variables

\begin{tabular}{lcccc}
\hline Variables & Control & $\begin{array}{c}\text { L-NAME } \\
\text { Pregnant rats }\end{array}$ & DEXA & L-NAME+DEXA \\
\cline { 2 - 5 } Glucose (mEq/L) & $134.83 \pm 38.45$ & $93.13 \pm 37.78$ & $86.88 \pm 12.63$ & $111.50 \pm 46.64$ \\
Abs. Left Kid. Wt (g) & $0.96 \pm 0.12$ & $0.89 \pm 0.13$ & $0.80 \pm 0.04$ & $0.87 \pm 0.13$ \\
Rel. Left Kid. Wt. (\%) & $0.0030 \pm 0.00027$ & $0.0028 \pm 0.00047$ & $0.0028 \pm 0.00021$ & $0.0033 \pm 0.00047$ \\
Adrenal Glands Wt. (g) & $0.08 \pm 0.02$ & $0.10 \pm 0.02$ & $0.09 \pm 0.01$ & $0.07 \pm 0.01$ \\
Urine Vol. (mL/24h) & $2.59 \pm 3.48$ & $5.25 \pm 7.31$ & $4.83 \pm 5.86$ & $3.56 \pm 1.74$ \\
Urinary Protein (g/dL) & $0.80 \pm 0.84$ & $1.00 \pm 0.00$ & $0.33 \pm 0.71$ & $1.75 \pm 0.89$ \\
Numbers of Fetuses & $7.57 \pm 3.60$ & $10.00 \pm 3.07$ & $13.22 \pm 1.86$ & $10.22 \pm 2.95$ \\
Total Wt of Fetuses (g) & $43.96 \pm 19.54$ & $50.75 \pm 14.66$ & $58.14 \pm 15.04$ & $41.96 \pm 15.34$ \\
\hline
\end{tabular}

Kid; Kidney, Abs: absolute, Rel: relative, Vol: volume, Wt: weight 
difference was found for systolic blood pressure at day 19. There was a significant effect of the time on systolic blood pressure of animals $(P=0.011)$, and a significant interaction has occurred between time and interventions in this respect $(\mathrm{P}=0.005)$.

No significant difference was in mean diastolic blood pressure values of pregnant Wistar albino rats when measured before intervention at day 15 . Post hocs did also not confirm the difference between mean diastolic blood pressures of control and L-NAME groups ( $\mathrm{P}=0.098, \% 95 \mathrm{Cl}:-2.716166-44.132833)$. However, the diastolic blood pressure values at 19th day of the experiment revealed significant differences between groups, indicating important effects of the interventions $(P=0.043)$. Post hocs revealed that the difference between DEXA and L-NAME + DEXA groups is significant $(P=0.044)$. Time had no important effect, and no significant interaction could be detected between time and interventions in this respect.

Mean diastolic blood pressure values of nonpregnant Wistar albino rats showed significant differences before interventions at day 15 of the experiment. Post hocs confirmed the difference between mean diastolic blood pressure values of the control and L-NAME + DEXA groups $(P=0.035)$. In contrast, the differences between the mean diastolic blood pressure values at day 19 was not confirmed statistically $(\mathrm{P}=0.083, \mathrm{~F}=2,506)$. However, ANOVA for repeated measures in factor time confirmed the effect of time $(P=0.001)$ and its interactions with interventions $(P=0.005)$.

Blood glucose concentrations: The mean blood glucose concentrations of animals are seen in Table 3. Statistical analyses did not confirm the effects of interventions on blood glucose concentrations of the pregnant Wistar albino rats $(P=0.088, F=2.424)$. Similarly, multiple comparisons did not confirm the difference between control and DEXA groups $(P=0.090, \% 95 \mathrm{Cl}:-5.403682-101.320349)$.

In contrast, the interventions had significant effects on blood glucose concentrations of nonpregnant Wistar albino rats $(P=0.008)$. Mean blood glucose concentrations of control and L-NAME groups was higher than that of the DEXA group ( $P=0.017$ and $\mathrm{P}=0.025$, respectively).

Kidney weights: Only the left kidney's weights were evaluated (Table 3). Statistical analyses indicated significant effects of the interventions on kidney weights of pregnant Wistar albino rats $(P=0.05$, $\mathrm{F}=2.929)$. Post hocs revealed higher mean kidney weight of controls than that of DEXA given group $(\mathrm{P}=0.032)$.

In contrast, no significant effect of interventions on kidney weights of non-regnant rats could be detected.

Weights of Adrenal Glands: The mean adrenal gland weights of animals are summarized in Table 3.

Statistical analyses showed that the weights of adrenal glands of the pregnant Wistar albino rats were influenced by interventions $(P=0.000)$. Post hocs showed that the mean weight of the adrenal glands of L-NAME given group was higher than those of control and L-NAME + DEXA given groups $(P=0.038$ and $P=0.000$, respectively). Similarly, the mean weight of the adrenal glands of the DEXA group was higher than that of animals given L- NAME + DEXA $(P=0.002)$.

However, interventions had no significant effect on mean adrenal gland weights of the non-pregnant animals.

Urine volumes and urinary protein concentrations: Average urine volumes and protein concentrations in the urine of pregnant and non-pregnant Wistar albino rats are shown in Table 3.

Statistical analyses of the data showed that interventions had no significant effect on 24-h urine volumes of pregnant Wistar albino rats, but their urinary protein excretions were influenced $(P=0.010)$. Post hocs revealed significantly lower urinary protein concentrations of DEXA than that of L-NAME + DEXA group ( $\mathrm{P}=0.005)$.

In non-pregnant rats, neither 24-h urine volumes nor urinary protein excretions were affected by interventions $(P>0.05)$.

Numbers and weights of the fetuses: The mean numbers of fetuses of pregnant Wistar rats and their total weights are seen in Table 3. ANOVA revealed significant effects of interventions $(P=0.005)$. The difference between control and DEXA groups was confirmed in post hocs $(P=0.003)$. However, total fetal weighs did not differ among groups.

\section{Discussion}

In studies using L-NAME interventions, the body weight changes of animals were rarely assessed. Available two studies indicate possible effects of LNAME on body weights. Osol et al. (2009) reported that L-NAME given in drinking water $(0.5 \mathrm{~g} / \mathrm{L})$ for 10 days had no effect on body weights of non-pregnant rats, but body weights of pregnant animals receiving $L$ -NAME were in mean $5 \%$ lower than those of pregnant controls. Ribeiro et al. (1992) observed also a slowed growth of the rats with chronic L-NAME application. In contrast, short or long-term DEXA causes a decrease in body weight of animals (Beatty et al., 1971; Tonolo et al., 1988; Michel and Cabanac, 1999; Franco-Colin et al., 2006). Tonolo et al. (1988) 
reported $10 \mathrm{~g}$ weight loss per week when rats were given $10 \mu \mathrm{g}$ DEXA per day for 4 weeks. Motta et al. (2015) reported that DEXA decreased the body weights of non-pregnant animals significantly, and it abolished the weight gain of pregnant animals. Also, dexamethasone administered by continuous infusions (16 $\mathrm{\mu g} / \mathrm{kg} / \mathrm{h} / \mathrm{sc}$ ) to pregnant rats from day 16 of gestation resulted in a $30 \mathrm{~g}$ cumulative weight gain from day 15 to 21 of gestation while the cumulative weight gains of controls was $80 \mathrm{~g}$ in this time-period (Mostello et al. 1981).

The findings of this study reveal that the effects of L-NAME, DEXA, and L-NAME + DEXA combination depend on the physiological conditions (being pregnant or not pregnant) of female Wistar rats. Compared to controls, L-NAME and DEXA resulted in a slower weight gain while L-NAME + DEXA caused a slight decrease in body weights of pregnant animals within five days. However, all of these interventions caused decreases in mean body weights of nonpregnant rats (Table 1). Thus, these findings indicate that DEXA with or without L-NAME has a significant negative effect on body weights of the rats, in general.

Findings of previous studies suggested also that the applications of L-NAME and DEXA result in significant increases in systolic and diastolic blood pressures of pregnant and non-pregnant female rats (Kemse et al., 2014; Tain et al., 2014; Safaeian et al., 2015). Initially, the mechanism of hypertension by the L-NAME application has been explained via NOS inhibition. Findings from recent studies, however, suggested the involvement of a very complex regulation network including several factors in the development of hypertension by L-NAME. These include among others the renal angiotensinconverting enzyme (Giani et al., 2014), thromboxane (Francois et al., 2008), peroxisome proliferatoractivated receptor gamma (PPAR- $\psi$ ) (Kriska et al., 2014) and glucocorticoids (Wallerath et al., 1999).

Observations of modified effects of L-NAME in stress situations with high levels of endogenous glucocorticosteroids or by applications of synthetic glucocorticoids (Li et al., 1992; Wen et al., 2000) indicated possible interactions between L-NAME and glucocorticoids regarding the development of hypertension. Various studies revealed that these interactions have both synergistic and antagonistic properties (Changbin and Baylis, 2000; Li et al., 1992; Wen et al., 2000). Accordingly, as many other effects, the hypertensive effects of glucocorticoids are also mediated partly via suppression of the endothelial nitric oxide synthetase (eNOS) expression (Liu et al.,
2009). Also, pregnancy seemingly alters the sensibility of the organism to L-NAME and DEXA (Nathan et al., 1995; Li et al., 2003; Losonczy et al., 1996; Troiano et al., 2016). Consequently, the effects of these substances on the cardiovascular system of pregnant and non-pregnant animals may differ. The findings of this study, however, did not support the findings of other studies, which clearly demonstrated that both LNAME and DEXA applications induce hypertension, and, they have additive or synergic effects when used in combination in this respect (Changbin and Baylis, 2000; Wen et al., 2000; Lou et al., 2001).

The findings are also consistent with previous evidence gathered from human studies that L-NAME significantly increases blood pressure in healthy individuals, but not in hypertensive patients (Calver et al., 1992). However, the finding of this study did not support the hypertensive effects of L-NAME and glucocorticoids in this case DEXA in rats, and so far did not support preliminary studies cited above. The reasons may be multiple. First of all, basal blood pressures of animals in both control groups of this study are relatively high and indicate a possible spontaneous hypertension in the colony. The reason of this in the colony is not known exactly, but, basing to our recent experiences, it is assumed to be a dietary orgin, because of the blood pressure in the colony is normalized by changing diet. There is evidence that the cardiovascular system of dietinduced hypertensive animals is relatively resistant to NOS inhibition (Roberts et al. 2000).

These findings give also evidence that the effects of L-NAME and/or DEXA are modifiable by physiologic condition, in this case, the pregnancy. A finding, which is in accordance with preliminary studies, cited above. Tong et al. (1997) found significant increases in blood glucose concentrations of normotensive and spontaneously hypertensive Wistar-Kyoto rats given $20 \mathrm{mg} / \mathrm{kg}$ BW L-NAME for 4 consecutive days. DEXA also induces a significant increase in blood glucose concentrations of rats (Koricanac et al., 2006; Sood and Ismail-Beigi, 2010). However, Motta et al. (2015) reported a significant decrease in fasting glycaemia of pregnant animals which was absent on non-pregnant animals. Also in this study, DEXA failed to increase blood glucose concentrations, but the findings indicated that DEXA might work differently depending on if animals are pregnant or not.

No information was available about the effects of L-NAME on kidney weights. Jennings and Ferguson (Jennings and Ferguson, 1984) could not observe any effect of DEXA on kidney weights in rats, whereas 
Rooman et al. (1999) reported a dose-dependent decrease in mice. In this study, only the average kidney weight of pregnant animals was lower than that of controls.

Also, no information was available about the effects of L-NAME on weights of adrenal glands in rats. Lesniewska et al. (1992) applied 15, 30 or 60 mg DEXA per $100 \mathrm{~g}$ BW of rats for 7 days and observed a remarkable decrease in their adrenal gland weights. This effect was reversible and resolved within 7 days after the last application. The findings of this study showed that when compared to the control group, a significant increase in adrenal gland weight was seen only in pregnant rats by giving L-NAME. However, the addition of DEXA had an adverse effect to L-NAME alone.

A common finding of L-NAME-induced hypertension is the proteinuria. Rats given L-NAME in drinking water caused a decrease in glomerular filtration rate and a progressive increase in protein excretion in 24-h urine samples (Qiu et al., 1998). In

\section{References}

Adeagbo, A. S., \& Triggle, C. R. (1993). Interactions of nitric oxide synthase inhibitors and dexamethasone with alphaadrenoceptor-mediated responses in rat aorta. British Journal of Pharmacology, 109(2), 495-501.

Baker, M., Rahman, T., Hall, D., Avery, P. J., Mayosi, B. M., Cornell, J. M., Farall, M., Watkins, H., \& Keavney, B. (2007). The C-532T polymorphism of the angiotensinogen gene is associated with pulse pressure: a possible explanation for heterogeneity in genetic association studies of AGT and hypertension. International Journal of Epidemiology, 36(6), 1356-1362.

Beatty, W. W., Scouten, C. W., \& Beatty, P. A. (1971). Differential effects of dexamethasone and body weight loss on two measures of activity. Physiology and Behavior, 7(6), 869-871.

Bernatova, I. (2014). Endothelial dysfunction in experimental models of arterial hypertension: cause or consequence? BioMed Research International, 2014:598271. doi: 10.1155/2014/598271.

Calver, A., Collier, J., Moncada, S., \& Vallance, P. (1992). Effect of local intra-arterial NG-monomethyl I-arginine in patients with hypertension: the nitric oxide dilator mechanisms appears abnormal. Journal of Hypertension, 10, 1025-1031.

Cediel, E., Vazquez-Cruz, B., Navarro-Cid, J., de las Heras, N., SanzRosa, D., Cachofeiro, V., \& Lahera, V. (2002). Role of endothelin -1 and thromboxane $A 2$ in renal vasoconstriction induced by angiotensin $\mathrm{II}$ in diabetes and hypertension. Kidney International. Supplement, 62(82), 2-7.

Changbin, Q., \& Baylis, C. (2000). Dexamethasone worsens nitric oxide inhibition-induced hypertension and renal dysfunction. American Journal of Hypertension, 13(10), 1097-2002.

Franco-Colin, M., Villanueva, I., Pinon, M., \& Racotta, R. (2006). The effects of sympathectomy and dexamethasone in rats ingesting sucrose. International Journal of Biological Sciences, 2(1), 17-22.

Francois, H., Makhanova, N., Ruiz, P., Ellison, J., Mao, L., Rockman, H. A, \& Coffman, T. M. (2008). A role for the thromboxane receptor in I-NAME hypertension. American journal of physiology. Renal Physiology, 295(4), 1096-1102.

Giani, J. F., Janjulia, T., Kamat, N, Seth, D. M, Blackwell, L. B. W, this study, the lowest and highest urinary protein excretions were recorded in DEXA and L-NAME + DEXA given pregnant rats, respectively.

\section{Conclusion}

This study is designed to evaluate the effects of LNAME and DEXA, which were used routinely to produce hypertension in animal models, on blood pressure of female Wistar rats from a breeding colony with higher blood pressures seemingly due to dietary factors. The findings of this study indicate that the interventions caused no further increase in blood pressure in previously hypertensive animals and that the animals used are relatively resistant not only to LNAME induced hypertension but also to DEXA and to a combination thereof. Thus, assessment of possible mechanisms would be important in explaining the ethiopathologies of resistances and predispositions for the NO- and DEXA-mediated hypertensions or hypertensions with multiple ethiopatogenesis.

Shah, K. H, Shen, X. Z, Fuchs, S, Delpire, E, Toblli, J. E, Bernstein, K. E, McDonough, A. A, \& Gonzalez-Villalobos, R. A. (2014). Renal angiotensin-converting enzyme is essential for the hypertension induced by nitric oxide synthesis inhibition. Journal of the American Society of Nephrology, 25(12), 27522763.

Goodwin, J. E, Zhang, J, Gonzalez, D, Albinsson, S, Geller, D. S. (2011). Knockout of the vascular endothelial glucocorticoid receptor abrogates dexamethasone-induced hypertension. Jornal of Hypertension, 29(7), 1347-1356.

Jennings, A. S, Ferguson, D. C. (1984). Effect of dexamethasone on triiodothyronine production in the perfused rat liver and kidney. Endocrinology, 114(1), 31-36.

Kemse, N. G, Kale, A. A, \& Joshi, S. R. (2014). A combined supplementation of omega-3 fatty acids and micro nutrients (folic acid, vitamin B12) reduces oxidative stress markers in a rat model of pregnancy induced hypertension. PLoS One, 9(11), 111902.

Koricanac, G, Isenovic, E, Stojanovic-Susulic, V, Miskovic, D, Zakula, Z., \& Ribarac-Stepic, N. (2006). Time dependent effects of dexamethasone on serum insulin level and insulin receptors in rat liver and erythrocytes. General Physiology and Biophysics, 25(1), 11-24.

Kriska, T, Cepura, C, Gauthier, K. M, Campbell, W. B. (2014). Role of macrophage PPARy in experimental hypertension. American journal of physiology. Heart and Circulatory Physiology, 306(1), 26-32.

Lesniewska, B, Nowak, K. W, Malendowicz, L. K. (1992). Dexamethasone-induced adrenal cortex atrophy and recovery of the gland from partial, steroid-induced atrophy. Experimental and Clinical Endocrinology, 100(3), 133-139.

Li, L., Storey, P., Kim, D., Li, W., \& Prasad, P. (2003). Kidneys in hypertensive rats show reduced response to nitric oxide synthase inhibition as evaluated by BOLD MRI. Journal of Magnetic Resonance Imaging, 17(6), 671-675.

Li, M., Dusting, G. J., \& Whitworth, J. A. (1992). Inhibition of NO synthesis has an additive effect on hypertension induced by ACTH in conscious rats. Clinical and Experimental Pharmacology and Physiology, 19(10), 675-681. 
Liu, Y., Mladinov, D., Pietrusz, J. L., Usa, K., \& Liang, M. (2009). Glucocorticoid response elements and11ßhydroxysteroid dehydrogenases in the regulation of endothelial nitric oxide synthase expression. Cardiovascular Research Journal, 81(1), 140-147.

Losonczy, G., Mucha, I., Müller, V., Kriston, T., Ungvari, Z., Tornóci, L., Rosivall, L., \& Venuto, R. (1996). The vasoconstrictor effects of L-NAME, a nitric oxide synthase inhibitor, in pregnant rabbits. British Journal of Pharmacology, 118(4), 1012-1018.

Lou, Y. K., Wen, C., Li M., Adams, D. J., Wang, M. X., Yang, F., Morris, B. J., \& Whitworth, J. A. (2001). Decreased renal expression of nitricoxide synthase isoforms in adrenocorticotropin-induced and corticosterone-induced hypertension. Hypertension, 37(4), 1164-1170.

Michel, C., \& Cabanac, M. (1999). Effects of dexamethasone on the body weight set point of rats. Physiology and Behavior, 68(1), 145-150.

Mostello, D. J., Hamosh, M., \& Hamosh, P. (1981). Effect of dexamethasone on lipoprotein lipase activity of fetal rat lung. Biolology of the Neonate, 40, 121-128.

Motta, K, Ruiz, M. F., Bordin, S., \& Rafacho, A. (2015). Evaluation of lipid homeostasis in the late gestational period of rats exposed to dexamethasone. Diabetology and Metabolic Syndrome, 7(1), 74.

Nathan, L., Cuevas, J., \& Chaudhuri, G. (1995). The role of nitric oxide in the altered vascular reactivity of pregnancy in the rat. British Journal of Pharmacology, 114(5), 955960.

Osol, G., Barron, C., Gokina, N., \& Mandala, M. (2009). Inhibition of nitric oxide synthases abrogates pregnancyinduced uterine vascular expansive remodeling. Journal of Vascular Research, 46(5), 478-486.

Pennington, K. A, Schlitt, J. M, Jackson, D. L, Schulz, L. C, \& Schust, D. J. (2012). Preeclampsia: multiple approaches for a multifactorial disease. Disese Models and Mechanisms, 5(1), 9-18.

Podjarny, E., Losonczy, G., \& Baylis, C. (2004). Animal models in preeclampsia. Seminars in Nephrology, 24(6), 596-606.

Púzserová, A., Csizmadiová, Z., \& Bernátová, I. (2007). Effect of blood pressure on L-NAME-sensitive component of vasorelaxation in adult rats. Physiological Research, 56 (Suppl. 2), S77-S84.

Qiu, C., Muchant, D., Beierwaltes, W. H., Racusen, L., Baylis, C. (1998). Evolution of chronic nitricoxide inhibition hypertension: relationship to renal function. Hypertension, 31(1), 21-26.

Rafikov, R., Fonseca, F. V., Kumar, S., Pardo, D., Darragh, C., Elms, S., Fulton, D., \& Black, S. M. (2011). eNOS activation and NO function: structural motifs responsible for the post translational control of endothelial nitric oxide synthase activity. Journal of Endocrinology, 210(3), 271284.

Ribeiro, M. O., Antunes, E., de Nucci, G., Lovisolo, S. M., Zatz, R. (1992). Chronic inhibition of nitric oxide synthesis. A new model of arterial hypertension. Hypertension, 20(3), 298-303.

Roberts, C. K, Vaziri, N. D, Wang, X. Q, \& Barnard, R. J. (2000). Enhanced NO inactivation and hypertension induced by a high-fat, refined-carbohydrate diet.
Hypertension, 36, 423-429.

Rooman, R., Koster, G., Bloemen, R., Gresnigt, R., \& van Buul -Offers, S. C. (1999). The effect of dexamethasone on body and or gan growth of normal and IGF-II-transgenic mice. Journal of Endocrinology, 163(3), 543-552.

Safaeian, L., Ghannadi, A., Javanmard, S. H., Vahidian, M. H. (2015). The effect of hydroalcoholic extract of ferula foetida stems on blood pressure and oxidative stress in dexamethasone-induced hypertensive rats. Research in Pharmaceutical Sciences, 10(4), 326-334.

Sood, A., \& Ismail-Beigi, F. (2010). Effect of dexamethasone on insulin secretion: examination of under lying mechanisms. Endocrine Practice, 16(5), 763-769.

Tain, Y. L, Chen, C. C, Sheen, J. M, Yu, H. R, Tiao, M. M, Kuo, H. C., \& Huang, L. T. (2014). Melatonin attenuates prenatal dexamethasone-induced blood pressure increase in a rat model. Journal of the American Society of Hypertension, 8(4), 216-226.

ong, Y. C., Wang, C. J., \& Cheng, J. T. (1997). The role of nitric oxide in the control of plasma glucoseconcentration in spontaneously hypertensive rats. Neuroscience Letters, 233(2-3), 93-96.

Tonolo, G., Fraser, R., Connell, J. M., \& Kenyon, C. J. (1988). Chronic low-dose infusions of dexamethasone in rats: effects on blood pressure, body weight and plasma atrial natriuretic peptide. Jornal of Hypertension, 6(1), 25-31.

Török, J. (2008). Participation of nitric oxide in different models of experimental hypertension. Physiological Research, 57(6), 813-825.

Troiano, J. A., Potje, S. R., Graton, M. E., Cavalari, P., Pereira, A. A., Vale, G. T., Nakamune, A. C., Sumida, D. H., Tirapelli, C. R., Antonialli, C. (2016). Decreased reactive oxygen species production and NOX1, NOX2, NOX4 expression contribute to hyporeactivity to phenylephrine in aortas of pregnant SHR. Life Sciences Journal, 144, 178 $-184$.

Wallerath, T, Witte, K, Schafer, S. C, Schwarz, P. M, Prellwitz, W., Wohlfart, P., Kleinert, H., Lehr, H. A., Lemmer, B., \& Förstermann, U. (1999). Down-regulation of the expression of endothelial NO synthase is likely to contribute to glucocorticoid-mediated hypertension. Proceedings of the National Academy of Sciences of the United States of America, 96(23), 13357-13362.

Wen, C., Li, M., \& Whitworth, J. A. (2000). Role of nitric oxide in adrenocorticotrophin-induced hypertension: L-arginine effects reversed by $\mathrm{N}$-nitro-L-arginine. Clinical and Experimental Pharmacology and Physiology, 27(11), 887890.

WHO. (2005). Risking death to give life. World Health Organization, Geneva, Switzerland.

Yallampalli, C., Byam-Smith, M, Nelson, S, Garfield, R. E. (1994). Steroid hormones modulate the production of nitric oxide and CGMP in the rat uterus. Endocrinology, 134, 1971-1974.

Zhang, L. N., Ji, L. D., Fei, L. J., Yuan, F., Zhang, Y. M., Xu, J. (2013). Association between polymorphisms of alphaadducin gene and essential hypertension in Chinese population. BioMed Research International, 2013:451094. doi: 10.1155/2013/451094. 